\title{
pSTAT5 and ERK exhibit different expression in myeloproliferative neoplasms
}

\author{
EWA WIŚNIEWSKA-CHUDY ${ }^{1,5}$, ŁUKASZ SZYLBERG $^{1}$, GRZEGORZ DWORACKI $^{2}$, \\ EWA MIZERA-NYCZAK ${ }^{3}$ and ANDRZEJ MARSZAŁEK ${ }^{1,4}$
}

\begin{abstract}
${ }^{1}$ Department of Clinical Pathomorphology, Nicolaus Copernicus University in Toruń, Collegium Medicum in Bydgoszcz, 85-092 Bydgoszcz; ${ }^{2}$ Department of Clinical Immunology, Poznań University of Medical Sciences, 60-806 Poznań;

${ }^{3}$ Department of Oncology, Greater Poland Cancer Centre, 61-866 Poznań; ${ }^{4}$ Department of Oncologic Pathology,

Poznań University of Medical Sciences and Greater Poland Cancer Center, 61-866 Poznań, Poland
\end{abstract}

Received October 19, 2016; Accepted December 2, 2016

DOI: 10.3892/or.2017.5476

\begin{abstract}
Myeloproliferative neoplasms (MPNs) are clonal hematopoietic progenitor cell disorders characterized by the proliferation of one or more hematopoietic lineages. The classical MPNs include polycythemia vera (PV), essential thrombocythemia (ET) and primary myelofibrosis (PMF) entities. These disorders are characterized by bone marrow morphology typical for each disease, and by the presence of $J A K 2 V 617 F$ mutation in the marrow and blood. However, $J A K 2 V 617 F$ cannot account for the phenotypic heterogeneity of MPNs because approximately half of all cases of ET and PMF show no evidence of this molecular marker. Therefore, the search for novel markers of these diseases is necessary to improve pathomorphological and molecular diagnostics. This study aimed to investigate the changes in expression patterns of the proteins STAT5 (the signal transducers and activators of transcription 5) and ERK (extracellular signalregulated kinase) in bone marrow trephine specimens, derived both from patients with wild-type and mutant (V617F) forms of JAK2 kinase. Furthermore, the changes in STAT5 and ERK2 gene expression levels in the same patients were also investigated. The results of our immunohistochemical, immunoblotting and RT-qPCR studies revealed at least four major unique features of three types of MPNs. These include: i) more pronounced expression of phosphoSTAT5 protein in patients with JAK2V617F mutation compared to patients with wild-type of JAK2 kinase ii) different expression pattern of pSTAT5 in the nucleus and the cytoplasm of megakaryocytes and other bone marrow cells; iii) approximately 5-fold higher
\end{abstract}

Correspondence to: Dr Ewa Wiśniewska-Chudy, ${ }^{5}$ Present address: Department of Molecular Cell Genetics, Ludwik Rydygier Collegium Medicum Bydgoszcz, Nicolaus Copernicus University in Toruń, Skłodowskiej-Curie 9, 85-094 Bydgoszcz, Poland

E-mail: e.wisn@wp.pl

Key words: ERK, essential thrombocythemia, IHC, polycythemia vera, primary myelofibrosis, STAT5 expression level of STAT5a gene in PV in comparison to patients with PMF and approximately 2-fold higher than in ET patients; iv) different, intracellular expression patterns of ERK2 and ERK1/2 antigens allowed to distinguish each subtype of MPN. These abnormalities in expression patterns of STAT5 and ERK proteins and genes provide some novel molecular features of MPNs and brings us closer to explaining the pathogenesis of MPNs.

\section{Introduction}

Myeloproliferative neoplasms (MPNs) are a group of clinically related diseases characterized by extensive proliferation and expansion of one or more myeloid cell lineages in the bone marrow and peripheral blood, with relatively preserved differentiation $(1,2)$. MPNs are divided into Philadelphia chromosome (BCR-ABL) positive $\left(\mathrm{Ph}^{+}\right)$chronic myeloid leukemia (CML) and Philadelphia negative $\left(\mathrm{Ph}^{-}\right)$disorders including polycythemia vera (PV), essential thrombocythemia (ET), and primary myelofibrosis (PMF) (3). From the clinical and histopathological standpoints, the differentiation between the various types of MPN often presents difficulties, especially in cases of fibrosis or thrombocytosis. In addition, PV, ET and PMF can progress, usually after several years, to secondary myelofibrosis or, in rare cases, into acute leukemia (AML) (4-6). These secondary AML are associated with an extremely poor prognosis compared to de novo AML (4).

The genetic cause of MPNs was not known until 2005, when four independent groups (7-10) published that an identical, point mutation in Janus kinase 2 gene (JAK2), G to $\mathrm{T}$ substitution, at position 1849 , was present in the majority of $\mathrm{Ph}$-negative patients. This mutation occurs within the JAK homology domain 2 (JH2) pseudokinase and leads to substitution of valine by phenylalanine at codon 617 (V617F) of JAK2 tyrosine kinase $(7-9,11)$. This mutation causes constitutive phosphorylation of JAK2 protein and activation of substrate molecules such as STAT proteins and ERK (12). JAK2V617F mutation has been identified as a unifying event for typical MPNs, rarely occurring in other myeloid malignancies (13-16). The frequency of JAK2V617F version is approximately $65-97 \%$ in patients with PV, approximately $23-57 \%$ with ET, 
and $35-57 \%$ with PMF (8-11). The discovery of JAK2V617F allowed WHO to formulate a new definition of classification of MPNs, until 2008 called myeloproliferative disorders (17). JAK2 is a cytoplasmic protein kinase, a member of the signal transducers located downstream of cellular receptors such as EPO, IL-6, and GM-CSF receptor. JAK2 tyrosine kinase plays a critical role in the proliferation and differentiation of hematopoietic cells (18). In normal cells, ligand binding induces oligomerization of the receptor subunits, and subsequent activation of the JAKs. The JAK2V617F mutation causes a constitutive activation of JAK2 (19) and enhanced proliferation capacity even in the absence of the ligand $(8,9,11)$. The pathogenic significance of JAK2V617F has been demonstrated in a mouse model whereby transplanted bone marrow cells containing JAK2V617F led to the development of MPN features in the recipient mice $(11,20)$. It is noteworthy that high levels of retroviral expression of JAK2V617F in transgenic murine models have been associated with the development of PV-like phenotype $(11,20,21)$, whereas lower levels of JAK2V617F expression has induced in mice different MPN phenotypes, including ET and PMF-like disorders $(22,23)$.

Nevertheless, the identification of the $J A K 2 V 617 F$ mutation was a cardinal step in distinguishing BCR/ABL negative disorders from other hematologic diseases, the mechanisms of MPNs development are not thoroughly understood. Hence, further cellular and genetic characterization is needed. Cellular characterization is important especially for all pathomorphological laboratories, which are not well equipped with molecular biology assay tools, and immunohistochemistry is widely available. However, the discovery of JAK2V617F mutation has inspired an intensive search for novel molecular changes in MPNs, because it is not yet clear how single mutation can generate at least three different phenotypes (PV, ET and PMF) and also some other myeloid neoplasms with different clinical features and prognosis $(15,16,24,25)$. It is also unclear how it is possible that patients without $\mathrm{V} 617 \mathrm{~F}$ mutation in JAK2 gene can develop MPNs. That is why we searched for other factors in members of the JAK2 kinase signal transduction pathways, which could be markers distinguishing PV, ET and PMF entities; factors that may be involved in these pathological processes.

In our studies we collected data from a series of 132 patients with PV, ET, PMF and also from 17 healthy individuals as control group and then addressed the issue of whether i) the presence, distribution and protein expression level of transducer activator of transcription 5 (STAT5) and extracellular signalregulated kinases (ERK) 1 and 2, and ii) gene expression level of STAT5a and ERK2 in bone marrow trephine biopsies could clearly distinguish between each MPN. We selected these molecules, because they are the elements of JAK2/STAT and JAK2/Raf/MEK/ERK signalling pathways, which probably plays a critical role in the promotion of hematopoietic cells growth, prevention of apoptosis and consequently contribute to induction of MPNs. These pathways are constructively phosphorylated by V617F form of JAK2 kinase $(9,11,26)$.

\section{Materials and methods}

Bone marrow study group. The trephine biopsies were independently diagnosed at the Department of Clinical Pathology in Bydgoszcz by two experienced pathologists (A.M. and G.D.) based on the histopathological typing of the World Health Organization. Patient samples were collected between 2008 and 2013 in the Department of Clinical Pathomorphology of Dr Antoni Jurasz, University Hospital in Bydgoszcz. From more than 1000 cases, we selected 132 patient samples for this study. Out of these, 52 samples derived from patients suffered from PV (37 with JAK2V617F mutation), 41 from ET (22 with JAK2V617F mutation), and 22 from PMF (10 with JAK2V617F mutation) and 17 healthy controls with no signs of neoplastic proliferation.

Histopathological analysis. The bone marrow trephine biopsies were fixed in $5 \%$ neutral buffered formalin $(\mathrm{pH} 7.6)$ for $24 \mathrm{~h}$, at $4^{\circ} \mathrm{C}$ and then decalcificated with $0.1 \mathrm{M}$ ethylenediaminetetraacetic acid (EDTA) in phosphate-buffered saline (PBS) for $24 \mathrm{~h}$ at $4^{\circ} \mathrm{C}$. Then samples were dehydrated, passing through several changes of xylene and finally embedded in paraffin wax. This method has been found to offer excellent morphology, good antigen for immunohistochemical (IHC) reaction, satisfactory DNA and even RNA preservation for molecular studies (27). Fixation in neutral buffered formalin and decalcification with EDTA is also recommended by International Council for Standardization in Hematology (ICSH). Tissue samples for accurate pathological diagnosis were analyzed in 3-4 $\mu \mathrm{m}$ sections stained with $\mathrm{H} \& \mathrm{E}$, Gomori silver impregnation, periodic acid-Schiff (PAS), Masson trichrome and other histological stains. Then slides were viewed under light microscopy (BX51, Olympus Polska, Warszawa, Poland). The study was approved by the ethics committee of the Collegium Medicum in Bydgoszcz Nicolaus Copernicus University in Torun (approval no. 267/10).

Immunohistochemistry for pSTAT5, ERK2 and total ERK1/2 localization. The tissues were cut with an Accu-Cut SRM 200 rotary microtome (Sakura Finetek Europe B.V., Olympus Polska) into 3-4 $\mu \mathrm{m}$ sections, which were collected onto electrostatically charged Superfrost Plus glass slides (Thermo Scientific, Life Technologies, Polska, Warszawa, Poland) and dried on a warm plate. IHC reactions were performed with the use of several monoclonal antibodies in order to detect specific proteins within the cell components of bone marrow tissues. These were anti-pSTAT5, anti-ERK2 and anti-ERK1/2. The antibodies are characterized in detail in Table I.

Paraffin was removed from tissue sections by passing the slides through several changes of xylene, followed by tissue rehydratation in graded ethanols and finally in distilled water solutions. Antigens retrieval was carried out in water bath using Dako retrieval solution $\mathrm{pH} 9.0$, at $95^{\circ} \mathrm{C}$ for $40 \mathrm{~min}$. After cooling and rinsing in $0.01 \mathrm{M}$ PBS buffer $(0.138 \mathrm{M}$ $\mathrm{NaCl}, 0.03 \mathrm{M} \mathrm{Na}_{2} \mathrm{HPO}_{4}, 0.002 \mathrm{M} \mathrm{KH}_{2} \mathrm{PO}_{4}, \mathrm{pH}$ 7.4), the slides were incubated with $3 \% \mathrm{H}_{2} \mathrm{O}_{2}$ for $10 \mathrm{~min}$ for block endogenous peroxidases activity. Non-specific binding sites were blocked by $0.01 \mathrm{M}$ PBS containing $5 \%$ bovine serum albumin (BSA; Sigma-Aldrich, Poznań, Poland) for $10 \mathrm{~min}$. Then the primary antibodies, diluted in $0.01 \mathrm{M}$ PBS supplemented with $1 \%$ BSA (Table I) were applied for $16 \mathrm{~h}$ at $4^{\circ} \mathrm{C}$. At the next step, sections were incubated with secondary anti-rabbit antibody coupled to peroxidase (EnVision system, Dako, 
Gdynia, Poland), for $1 \mathrm{~h}$. Between each step, the sections were rinsed in pure PBS buffer. Reaction products were visualized with 3,3'- diaminobenzidine chromogen (DAB; Dako) for $5 \mathrm{~min}$. The reaction was stopped by using distilled water. Next, the slides were counterstained with Mayer's haematoxylin, dehydrated, cleared in xylene and finally mounted in Shandon Consul-Mount (Thermo Scientific, Life Technologies Polska).

All reactions took place at room temperature, except for incubation with antigens retrieval solution and with the panel of primary antibodies (Table I). The incubation with primary and secondary antibodies as well as with DAB was performed in a humid chamber. Negative control reactions were performed by leaving out the incubation with primary antibodies which were replaced by $1 \%$ BSA in $0.01 \mathrm{M}$ PBS.

Morphometric analysis. Interpretation of IHC staining was performed as described in detail earlier $(28,29)$. Remmele and Stegner (30) scoring system was used. The slides were viewed under light microscope Eclipse E800 (Nikon Instruments Europe, Amsterdam, The Netherlands) at a magnification of $\mathrm{x} 400$ and analyzed with the NIS-Elements 3.30 software (Nikon).

Preparation of protein extract and dot blot reaction. Proteins isolated from trephine biopsies derived from patients with ET, PV and PMF and from healthy control group were analyzed by using dot-blot assay. This technique allowed for immunodetection of pSTAT5, ERK2 and ERK1/2 antigens and their quantitative estimate in total protein extract.

Dot blot analysis was performed as previously described (29) with some modifications. In brief, the $10 \mu \mathrm{m}$ tissue sections were cut with an Accu-Cut SRM 200 rotary microtome. Depending on the size of patients trephine biopsy 5-7 sections to one protein extraction were used. The proteins were isolated by using Qproteome FFPE Tissue kit (Qiagen, Alab-Gen, Warszawa, Poland) dedicated to formalin-fixed, paraffinembedded tissues, in accordance with the provided protocol. All proteins concentrations ranged between 25-120 $\mu \mathrm{g} / \mu \mathrm{l}$ and were determined by using a Micro BCA Protein Assay kit (no. 23235; Thermo Fisher Scientific, Life Technologies Polska). It should be mentioned that the quality of obtained proteins was lower than protein quality isolated from fresh, not fixed in formalin and not embedded in paraffin tissue material. Protein quality was checked by using SDS-PAGE electrophoresis and staining protein gel with Coomassie Blue dye. Similar protein quality is recommended by the kit manufacturer Qiagen (Qproteome FFPE Tissue, Alab-Gen). Finally, for dot-blot assay only slightly degraded protein was used. The reaction was carried out on the protein isolated from 25 patients with PV (15 with JAKV617F mutation), 20 with ET (10 with JAKV617F mutation), 19 with PMF (9 with JAKV617F mutation) and also from 12 healthy persons.

Proteins were diluted to $30 \mu \mathrm{g} / \mu \mathrm{l}$. Two microliters $(60 \mu \mathrm{g})$ of each protein were slowly spotted onto membrane (BioRad Laboratories, Warszawa, Poland) and air-dried. Then membranes were incubated with 5\% BSA in TBST containing $0.1 \%$ Tween- 20 for $40 \mathrm{~min}$ at $25^{\circ} \mathrm{C}$. After the blocking, the membranes were incubated overnight at $4^{\circ} \mathrm{C}$ with the respective primary antibodies: anti-STAT5, anti-ERK2, anti-ERK1/2 
Table II. Primer sequences used for real-time PCR.

Gene/sequence identification no.

in GeneBank

Primer sequence (5'-3')

Size of qPCR amplicon

\section{GAPDH}

M17851.1

TBP

M55654.1

$\beta$-actin

NM_001101.3

PRGK1

NM_000291.3

STAT5a

NM_003152.3

ERK2

NM_003154.4
Forward (F): AGCCGAGCCACATCGCT

Reverse (R): TGGCAACAATATCCACTTTACCAGAGT

Forward (F): GCACAGGAGCCAAGAGTGAA

Reverse (R): TCACAGCTCCCCACCATGTT

Forward (F): CCCCGCGAGCACAGA

Reverse (R): CCACGATGGAGGGGAAGAC

Forward (F): GGGAAAAGATGCTTCTGGGAA

Reverse (R): TTGGAAAGTGAAGCTCGGAAA

Forward (F): GGCAAGGCCTGTAGAGAGTT

Reverse (R): TTGAGCCCCTTCAGAAAAGTCC

Forward (F): CGGAACTTGCAATCCTCAGT

Reverse (R): TCGTGTGGGTCCTGAATTGG
$125 \mathrm{bp}$

$127 \mathrm{bp}$

$171 \mathrm{bp}$

$75 \mathrm{bp}$

$76 \mathrm{bp}$

$76 \mathrm{bp}$ and anti-GAPDH antibodies (all described in detail in Table I). Then the membranes were washed 5 times in TBST buffer and incubated with secondary alkaline phosphatase conjugated antibody purchased from Sigma-Aldrich: mouse anti-rabbit (no. A2306) or rabbit anti-mouse (no. A4312). Both antibodies were diluted 1:4000 in TBST buffer with $0.2 \%$ BSA for $2 \mathrm{~h}$ at $22^{\circ} \mathrm{C}$. After rinsing in TBST buffer the dots were visualized by developing the membranes in substrate for alkaline phosphatase (NCBI/BCIP, no. B3679, Sigma-Aldrich, for $5 \mathrm{~min}$, at $22^{\circ} \mathrm{C}$. The reaction was stopped by washing several times in distilled water. The expression of pSTAT5, ERK2 and ERK1/2 proteins was comparable to those seen for GAPDH and analyzed by using Image $J$ software.

RNA isolation/reverse transcription reaction/relative quantification of STAT5a and ERK2 genes. RT-qPCR was performed to determine the transcription level of STAT5a and ERK2 genes in bone marrow samples (obtained by trephine biopsies) derived from patients with PV, ET, PMF and healthy individuals. The two genes mentioned above were selected for RT-qPCR analysis because after performing by the IHC and dot-blot reactions, STAT5a and ERK proteins encoded by these STAT5a and ERK2 genes showed differential expression levels in various disease entities within MPN.

Total RNA was extracted from seven $10 \mu \mathrm{m}$ paraffin-wax sections using NucleoSpin FFPE RNA kit (Marcherey-Nagel, Aqua Lab, Warszawa, Poland) according to the instructions provided by manufacturer. Then RNA was treated with DNase to remove any contaminating genomic DNA, by using RNasy Mini kit (no. 74106, Qiagen, Alab-Gen) according to manufacturer's instructions. The average yields of RNA isolation depending on the size of the biopsy was $20 \mu \mathrm{g}$. For further analysis only RNA on the quality of a specific absorbance ratio A260/A280 comprised in the range 1.90-1.98 was used. These values were measured spectrophotometrically using a NanoDrop ND-2000 spectrophotometer (Thermo Fisher Scientific, Life Technologies Polska). Finally for RT-qPCR the
RNA isolated from 20 patients with PV (14 with JAKV617F mutation), 17 with ET (10 with JAKV617F mutation), 14 with PMF (6 with JAKV617F mutation) and also from 11 healthy persons were used.

For cDNA synthesis 200 ng purified RNA and First Strand cDNA Synthesis kit (Thermo Scientific, Life Technologies, Polska) was used according to the manufacturer's instructions. Real-time PCR was performed in the final volume of $25 \mu 1$, in LightCycler 480 detection system (Roche Polska, Warszawa, Poland). The components of each reaction were: $100 \mathrm{ng}$ cDNA as template, $300 \mathrm{nM}$ forward and reverse primer (appropriate to the amplified sequence, Table II) and 1X Master mix (LightCycler 480 SYBR Green I Master; nr. 04887352 001; Roche Polska) including FastStart Taq DNA polymerase, reaction buffer, $\mathrm{dNTP}, \mathrm{MgCl}_{2}$ and SYBR Green I Dye. Primer pairs to STAT5a, ERK2 and housekeeping genes were designed on the $5^{\prime}$ border of one exon and $3^{\prime}$ border of the neighbouring exon to minimize the probability of DNA amplification instead of cDNA by using Primer3 software. Primer sequences are presented in Table II. A non-template control (RNase-free water) was included on each 96-well plate. Amplification was carried out for 45 cycles, and PCR cycle parameters were: i) for STAT5a: denaturation at $95^{\circ} \mathrm{C}$ for $15 \mathrm{sec}$; annealing at $56^{\circ} \mathrm{C}$ for $35 \mathrm{sec}$; extension at $72^{\circ} \mathrm{C}$ for $5 \mathrm{sec}$. ii) for ERK2: denaturation at $95^{\circ} \mathrm{C}$ for $15 \mathrm{sec}$; annealing at $58^{\circ} \mathrm{C}$ for $45 \mathrm{sec}$; extension at $72^{\circ} \mathrm{C}$ for $10 \mathrm{sec}$.

Additionally, in each $\mathrm{qPCR}$ reaction we carried out a melting curve, according to the follow program: $95^{\circ} \mathrm{C}$ for $7 \mathrm{sec} ; 65^{\circ} \mathrm{C}$ for $1 \mathrm{~min}$, to assess whether qPCR had generated specific and single reaction product.

Housekeeping gene to all qPCR experiments was selected from among four conventionally used genes to that purpose: glyceraldehydes-3-phosphate dehydrogenase (GAPDH), TATA box-binding gene (TBP), $\beta$-actin and protein kinase cGMP-dependent, type I (PRGK1). Finally, based on $\mathrm{C}_{t}$ values, we chose the first of these because the GAPDH gene expression was similar in all tissues analyzed. Therefore, the mRNA 
Table III. Comparative scoring of pSTAT5, ERK2 and pERK1/2 in patients with PV, ET, PMF and patients from control group. All results manifest non-normal distribution and are presented in the form of median and upper-lower quartiles range.

\begin{tabular}{|c|c|c|c|c|c|c|c|}
\hline \multirow[b]{2}{*}{ Antigen } & \multirow[b]{2}{*}{ Group 1} & \multicolumn{2}{|c|}{$\begin{array}{l}\text { Expression level } \\
\text { of group } 1\end{array}$} & \multirow[b]{2}{*}{ Group 2} & \multicolumn{2}{|c|}{$\begin{array}{l}\text { Expression level } \\
\text { of group } 2\end{array}$} & \multirow{2}{*}{$\begin{array}{c}\text { Significance } \\
\text { between group } 1 \\
\text { and } 2(\mathrm{P} \text {-value })\end{array}$} \\
\hline & & Median & $\begin{array}{c}\text { Upper-lower } \\
\text { quartiles }\end{array}$ & & Median & $\begin{array}{l}\text { Upper-lower } \\
\text { quartiles }\end{array}$ & \\
\hline \multirow[t]{15}{*}{ pSTAT5 } & PV JAK2- & 10.00 & $9.6-10.40$ & PV JAK2 ${ }^{+}$ & 11.70 & $11.35-11.90$ & $0.956^{\mathrm{b}}$ \\
\hline & ET JAK2- & 8.40 & $8.0-9.00$ & ET JAK2 ${ }^{+}$ & 11.40 & $11.0-11.70$ & $0.566^{\mathrm{b}}$ \\
\hline & PMF JAK2- & 5.20 & $4.6-5.70$ & PMF JAK $2^{+}$ & 6.10 & $5.6-6.30$ & $0.730^{\mathrm{b}}$ \\
\hline & PV JAK2- & 10.00 & $9.6-10.40$ & Control & 3.15 & $2.6-3.60$ & $0.001^{\mathrm{a}}$ \\
\hline & ET JAK2- & 8.40 & $8.0-9.00$ & Control & 3.15 & $2.6-3.60$ & $0.003^{\mathrm{a}}$ \\
\hline & PMF JAK2- & 5.20 & $4.6-5.70$ & Control & 3.15 & $2.6-3.60$ & $0.430^{\mathrm{b}}$ \\
\hline & PV JAK2 ${ }^{+}$ & 11.70 & $11.35-11.90$ & Control & 3.15 & $2.6-3.60$ & $0.001^{\mathrm{a}}$ \\
\hline & ET JAK2 ${ }^{+}$ & 11.40 & $11.0-11.70$ & Control & 3.15 & $2.6-3.60$ & $0.001^{\mathrm{a}}$ \\
\hline & PMF JAK2 ${ }^{+}$ & 6.10 & $5.6-6.30$ & Control & 3.15 & $2.6-3.60$ & $0.574^{\mathrm{b}}$ \\
\hline & PV JAK2- & 10.00 & $9.6-10.40$ & ET JAK2- & 8.40 & $8.0-9.00$ & $1.000^{\mathrm{b}}$ \\
\hline & PV JAK2- & 10.00 & $9.6-10.40$ & PMF JAK2- & 5.20 & $4.6-5.70$ & $0.001^{\mathrm{a}}$ \\
\hline & ET JAK2- & 8.40 & $8.0-9.00$ & PMF JAK2- & 5.20 & $4.6-5.70$ & $0.004^{\mathrm{a}}$ \\
\hline & PV JAK2+ & 11.70 & $11.35-11.90$ & ET JAK2 ${ }^{+}$ & 11.40 & $11.0-11.70$ & $1.000^{\mathrm{b}}$ \\
\hline & PV JAK $2^{+}$ & 11.70 & $11.35-11.90$ & $\mathrm{PMF}^{\mathrm{JAK}} 2^{+}$ & 6.10 & $5.6-6.30$ & $0.001^{\mathrm{a}}$ \\
\hline & ET JAK2 $2^{+}$ & 11.40 & $11.0-11.70$ & $\mathrm{PMF}_{\mathrm{JAK}} 2^{+}$ & 6.10 & $5.6-6.30$ & $0.001^{\mathrm{a}}$ \\
\hline \multirow[t]{10}{*}{ ERK2 } & PV JAK2- & 7.25 & $7.05-8.80$ & PV JAK2+ & 4.40 & $3.3-4.60$ & $0.005^{\mathrm{a}}$ \\
\hline & PV JAK2- & 7.25 & $7.05-8.80$ & ET & 11.25 & $11.0-11.30$ & $0.425^{\mathrm{b}}$ \\
\hline & PV JAK2- & 7.25 & $7.05-8.80$ & PMF & 6.80 & $6.2-7.50$ & $0.931^{\mathrm{b}}$ \\
\hline & PV JAK2- & 7.25 & $7.05-8.80$ & Control & 8.55 & $7.6-9.60$ & $1.000^{\mathrm{b}}$ \\
\hline & PV JAK2 ${ }^{+}$ & 4.40 & $3.3-4.60$ & ET & 11.25 & $11.0-11.30$ & $0.001^{\mathrm{a}}$ \\
\hline & PV JAK2 ${ }^{+}$ & 4.40 & $3.3-4.60$ & PMF & 6.80 & $6.2-7.50$ & $1.000^{\mathrm{b}}$ \\
\hline & PV JAK2 ${ }^{+}$ & 4.40 & $3.3-4.60$ & Control & 8.55 & 7.6-9.60 & $0.003^{\mathrm{a}}$ \\
\hline & ET & 11.25 & $11.0-11.30$ & PMF & 6.80 & $6.2-7.50$ & $0.958^{\mathrm{b}}$ \\
\hline & ET & 11.25 & $11.0-11.30$ & Control & 8.55 & $7.6-9.60$ & $0.630^{\mathrm{b}}$ \\
\hline & PMF & 6.80 & $6.2-7.50$ & Control & 8.55 & $7.6-9.60$ & $1.000^{\mathrm{b}}$ \\
\hline \multirow[t]{6}{*}{ ERK1/2 } & PV & 7.10 & $6.95-8.00$ & ET & 9.80 & $9.3-10.20$ & $0.908^{b}$ \\
\hline & PV & 7.10 & $6.95-8.00$ & PMF & 7.20 & $6.9-7.40$ & $1.000^{\mathrm{b}}$ \\
\hline & PV & 7.10 & $6.95-8.00$ & Control & 10.20 & $9.7-11.00$ & $0.830^{\mathrm{b}}$ \\
\hline & ET & 9.80 & $9.3-10.20$ & PMF & 7.20 & $6.9-7.40$ & $1.000^{\mathrm{b}}$ \\
\hline & ET & 9.80 & $9.3-10.20$ & Control & 10.20 & $9.7-11.00$ & $1.000^{\mathrm{b}}$ \\
\hline & PMF & 7.20 & $6.9-7.40$ & Control & 10.20 & $9.7-11.00$ & $0.986^{\mathrm{b}}$ \\
\hline
\end{tabular}

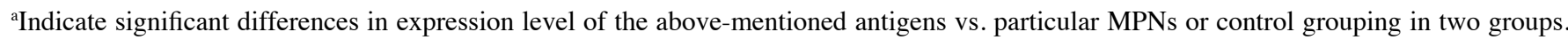
${ }^{b}$ Lack of significance. Differences are significant at the 0.05 level $(\mathrm{p}<0.05)$.

levels of STAT5a and ERK2 are expressed as the ratio of STAT5a/GAPDH and ERK2/GAPDH, respectively. The relative quantification was performed using the $\Delta \Delta^{\mathrm{Ct}}$ method (31). As calibrator we used cDNA from healthy patients. The primer sequences used for the real-time PCR to GAPDH, TBP, $\beta$-actin and PRGK1 are listed in Table II.

Statistical analysis. Statistical analysis of the results was performed using Statistica 9.0 software. The distribution of all results was analysed with Kolmogorov-Smirnov test with Lilliefors correction and with the Shapiro-Wilk test. Finally, the significance of differences was analysed with the use of non-parametric Kruskal-Wallis test for multiple comparison for results with non-normal distribution. Differences were considered statistically significant at a p-value $<0.05$.

\section{Results}

The presence, spatial distribution and relative abundance of STAT5 and ERK proteins which are the elements of JAK2/STAT and Raf/MEK/ERK signalling pathways were traced by the IHC and dot-blot detection by using monoclonal 
(phosphoSTAT5) and polyclonal (ERK2 and ERK1/2) antibodies. Additionally, relative expression level of pSTAT5a and ERK2 gene were examined in order to answer the question whether expression levels of pSTAT5 and ERK2 proteins and their mRNA level overlap. Three types of MPNs were involved in the study with the aim to establish whether the expression level of the studied proteins and genes are similar or different between PV, ET, PMF and control cases. Furthermore, it was also important to determine whether there are differences in expression of the studied proteins and genes between tissues with wild-type and V617F version of JAK2 kinase.

Correlation between the presence of $V 617 F$ and expression of pSTAT5a protein. Generally, IHC detection of STAT5 protein, phosphorylated on tyrosine residue 694 (Tyr694) under the light microscope revealed less pronounced expression level in patients with wild-type of JAK2 kinase (Fig. 1A-C), as compared to the patients expressing JAK2 with V617F mutation (Fig. 1E-G). However, these differences were not statistically significant $(\mathrm{p}=0.566-0.956$; Table III). Results were statistically significant when we compared pSTAT5 expression level between control cases and PV or ET with wild-type of JAK2 kinase ( $\mathrm{p}=0.001$ and 0.003 , respectively; Table III); and between control cases and PV or ET with V617F mutation ( $\mathrm{p}=0.001$ for both subtypes of MPNs; Table III).

Additionally, it should be distinctly noted that the highest expression level of pSTAT5 protein was observed predominantly in approximately $75 \%$ of the nucleus of bone marrow cells expressing JAK2V617F (Fig. 1E-G). It was clearly seen mainly in ET (Fig. 1F) and slightly less pronounced in PMF (Fig. 1G). Their nuclei were rich in pSTAT5 antigen, and the cytoplasm was completely lacking the signal or only scarcely labelled (Fig. 1F). In contrast, PV bone marrow cells with V617 mutation were characterized by widespread distribution of epitopes that recognized pSTAT5 antibody (Fig. 1E). Although they were present both in the nucleus and in the cytoplasm, their intracellular expression was relatively stronger in the nucleus (Fig. 1E). However, among studied MPNs with wild-type JAK2 kinase, brown signal derived from pSTAT5 was observed (similar to PV with JAK2V617F) both in the nucleus and in the cytoplasm (Fig. 1A-C) but their intracellular expression was on similar level (Fig. 1A-C). Thereby, the pSTAT5 signal derived from bone marrow cells was homogeneous (Fig. 1A-C).

Additionally, we observed that, regardless of the JAK2V617F presence, expression of pSTAT5 protein in PV and ET concerned almost all bone marrow cells (Fig. 1A, B, E and F), whereas in PMF it was observed only in approximately $50 \%$ bone marrow cells. Other cells were unmarked (Fig. 1C and G). Regarding the statistical significant relationships between particular MPNs with wild-type of JAK2 kinase and between particular MPNs with JAKV617F mutation, statistical significance was detected between expression level of pSTAT5 protein in PV and PMF ( $\mathrm{p}=0.001$; Table III) and also between ET and PMF ( $p=0.001-0.004$; Table III). On the contrary, no significant correlations were found between PV and ET ( $\mathrm{p}=1.000$; Table III).

pSTAT5a protein expression on megakaryocytes. Further differences observed between MPNs entities are reflected in
Table IV. The presence and relative abundance of ERK2 and ERK1/2 antigens in megakaryocytes observed after IHC reaction onto slides derived from patients with PV, ET, PMF and healthy controls.

\begin{tabular}{llllll}
\hline & \multicolumn{2}{c}{ ERK2 } & & \multicolumn{2}{c}{ ERK1/2 } \\
\cline { 2 - 3 } \cline { 5 - 6 } Patients & Nucleus & Cytoplasm & & Nucleus & Cytoplasm \\
\hline PV & $++/+++$ & + & & - & ++ \\
ET & +++ & ++ & & ++ & ++ \\
PMF & + & + & & + & $+/++$ \\
Control & ++ & + & & ++ & $++/+++$ \\
\hline
\end{tabular}

-, Antigen not present; +, antigen present; ++, antigen present in abundance; +++ , antigen present in great abundance; $+/++$, two different images, i.e., + and ++ were obtained depending on the sample; $++/+++$, two different images, i.e., ++ and +++ were obtained depending on the sample.

pSTAT5 expression pattern in megakaryocytes (Fig. 1, only inside images). In normal cases, pSTAT5 expression is limited to the cytoplasm of bone marrow cells (Fig. 1D, inside). While, in all analyzed MPNs, epitopes that bind STAT5 are mainly localized in the nucleus of megakaryocytes (Fig. 1A-C and E-G, inside). However, the cytoplasm of MPNs revealed different expression pattern of this protein. In all analysed MPNs with JAK2 V617F positive, the cytoplasm showed only trace amount of recognized epitope. In PV, ET and PMF without JAK2 V617F mutation we could distinguish several grades of expression: extremely rich in PV (Fig. 1A, inside), strong in ET (Fig. 1B, inside) and present in trace amount or absence in PMF (Fig. 1C, inside).

Diverse expression patterns of unphosphorylated ERK2 and ERK1/2 antigens in MPNs. Immunohistochemical comparison of the three disorders among MPNs revealed that both similarities and differences exist between them in terms of presence, relative abundance and cellular localization of two ERK antigens (Fig. 2; Tables III and IV). These antigens were recognized by two different antibodies, ERK 2 and ERK1/2 derived from Abcam and Cell Signaling Technology, respectively. Detailed information on specificity of antibodies used are presented in Table I.

The similarities were the relative abundance of antigens recognized by ERK antibodies. Both antigens are richly present within the bone marrow cells of PV, ET, PMF and healthy individuals (Fig. 2; Tables III and IV), and small differences in their expression levels were not statistically significant $(\mathrm{p}=0.425$ 1.000; Table III), except ERK2 expression level in PV. When we compared differences in expression level of ERK2 between tissues with and without V617F mutation of JAK2 kinase, results were statistically significant $(\mathrm{p}=0.005)$. Additionally statistical differences concerning ERK2 expression level were indicated between PV with JAK2V617F and ET $(\mathrm{p}=0.001)$ and between PV with JAK2-positive and control group $(\mathrm{p}=0.003)$.

The most important differences, but not statistically measured, are connected with intracellular localization of 

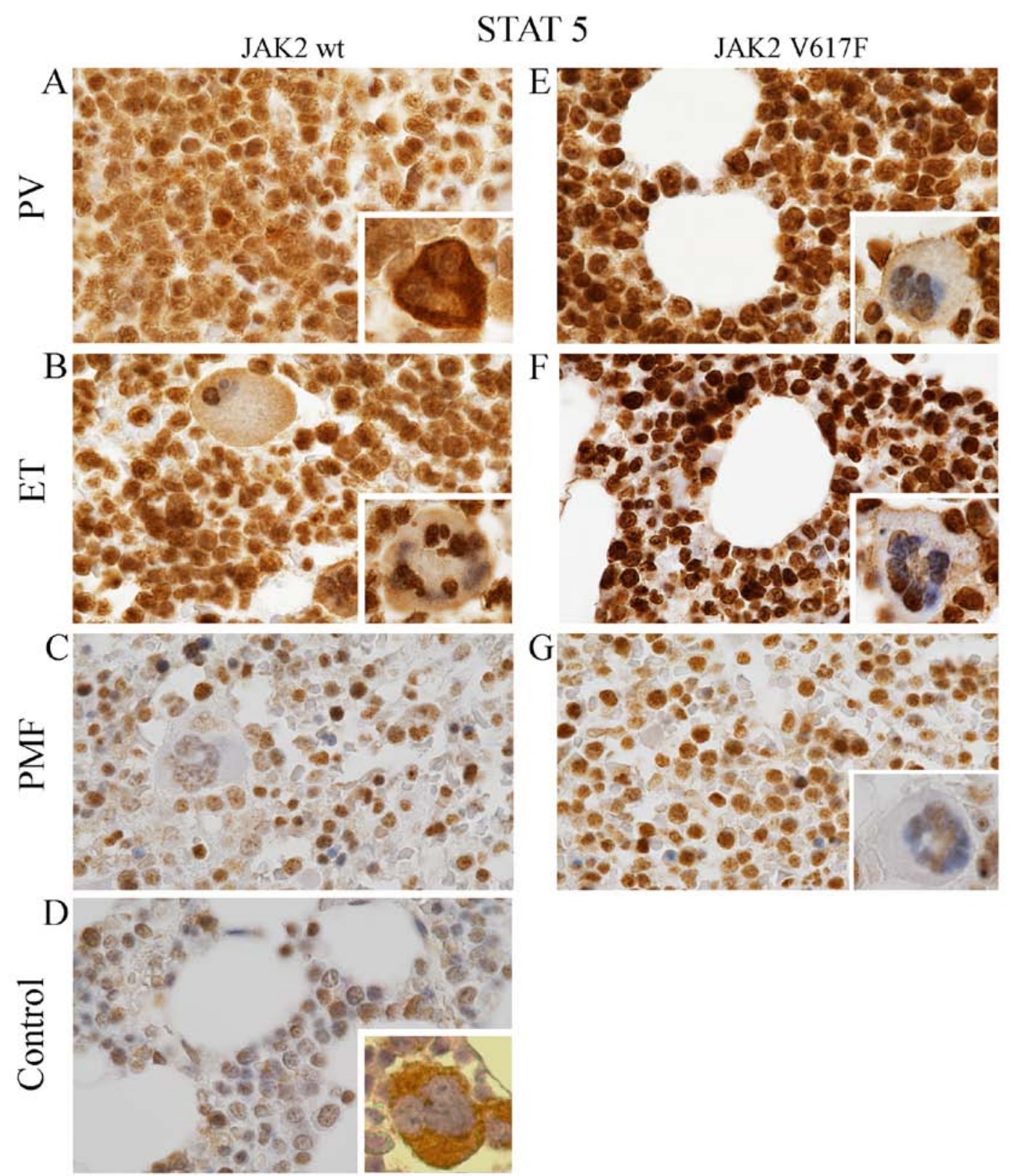

Figure 1. Expression of pSTAT5 protein in MPNs and in normal cases. Bone marrow trephine specimens derived from patients both with wild-type (A-D) and mutated (E-G) form of JAK2 kinase were evaluated by using Remmele and Stegner scoring system (30). Signal was different in intensity and intracellular localization. Generally, pSTAT5 expression was distinctly lower in samples with wild-type JAK2 (A-D) compared to JAK2V617F (E-G). Moreover, positive expression of this antigen was relatively high in PV (A and E) and ET samples (B and F) compared to PMF (C and G) and to control cases (D). Except PV with wild-type JAK2 (A inside image), pSTAT5 was mainly localized in the nuclei of MPNs megakaryocytes, whereas the cytoplasm is only slightly labelled (B and C, E-F, mainly inside images) or free of pSTAT5 antigens (G inside). Inversely, in control cases (D, inside), pSTAT5 is primarily located in the cytoplasm of megakaryocytes. Similarly in PV with JAK2-negative, pSTAT5 antigens is primarily localized in the cytoplasm, but the signal from the nuclei is lower (A, inside images). All images were taken under microscopic magnification of x1000.

ERK antigens. Although, the ERK proteins were detected both in the nucleus and cytoplasm of bone marrow cells, their expression level within these cell compartments were different in each MPN entity (Fig. 2; Table IV).

The nucleus exhibits differential expression patterns of ERK2 within the MPNs (Fig. 2; Table IV). The highest signal derived from cell nucleus was observed in PV and ET (Fig. 2A-C; Table IV), slightly lower in normal trephine biopsies (Fig. 2E; Table V), and the lowest in the PMF (Fig. 2D, Table IV). Additionally, it is worth noting that the highest expression levels of ERK2 antigens in PV were observed only in approximately $30 \%$ nucleus with JAK2V617F mutation and in approximately $80 \%$ nucleus without V617F version of JAK2 kinase (Fig. 2A and B). The cytoplasm of MPNs exhibit equally diverse pattern of ERK2 protein expression level. Distinct differences were demonstrated in PV between trephine biopsies with wild-type JAK2 (Fig. 2A; Table IV) and JAK2V617F (Fig. 2B; Table IV). In the first case, the cytoplasm was characterized by relatively high expression level of ERK2 (Fig. 2A; Table IV), whereas in the second case, ERK2 epitopes were absent or only scarcely represented in the cytoplasm (Fig. 2B; Table IV). In contrast to 


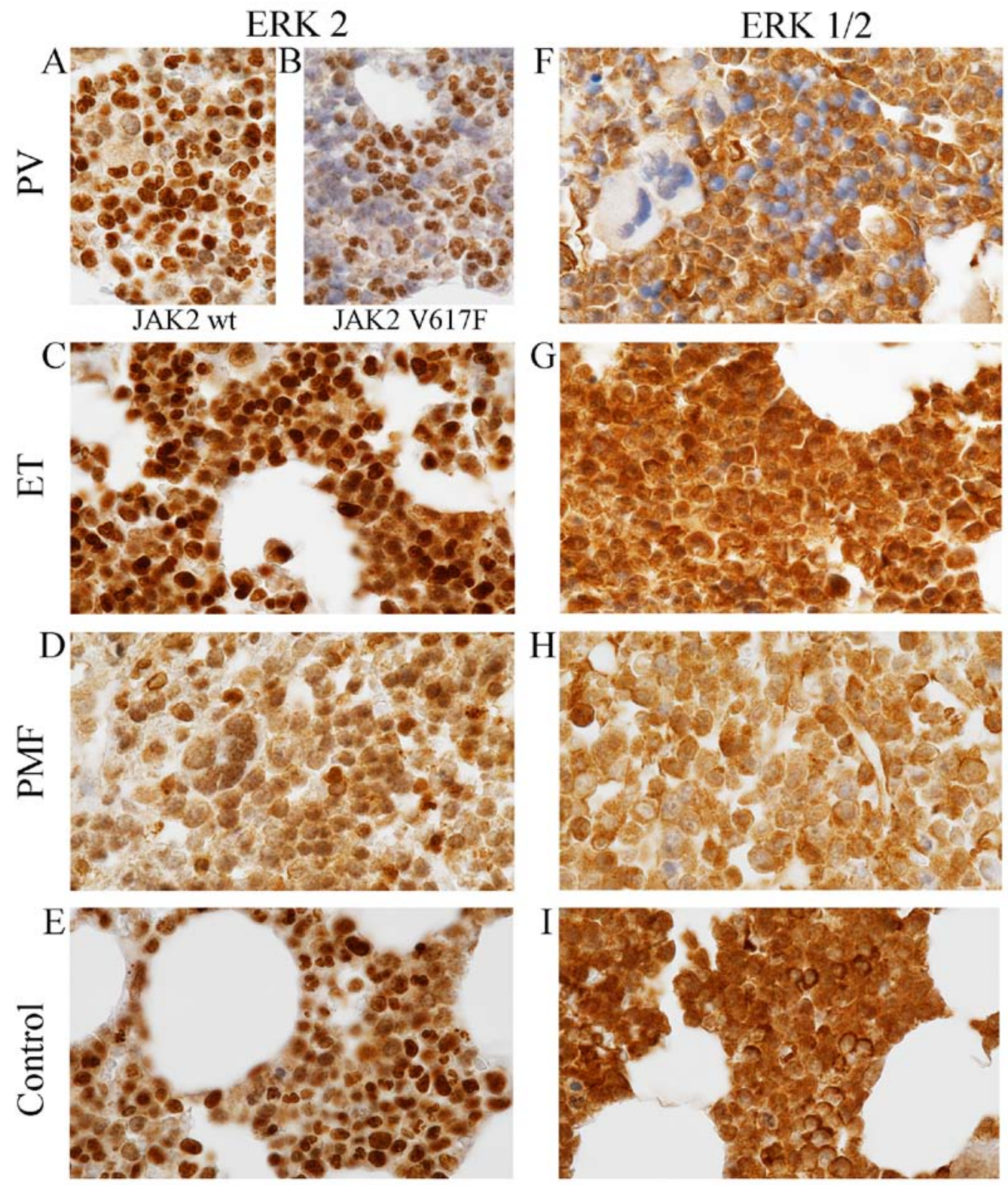

Figure 2. Differential intensity of signal with ERK2 (A-E) and ERK1/2 (F-I) antibody in PV (A, B and F), ET (C and G), PMF (D and H) and control bone marrow tissues (E and I). All images were taken under microscopic magnification of x1000.

PV (Fig. 2A and B; Table IV), in the cytoplasm of ET, PMF and control cells (Fig. 2C-E; Table IV) we did not observe differences depending on presence JAK2V617F mutation concerning expression pattern of ERK2 antibody. In ET they could be identified in the cytoplasm in relatively high levels (Fig. 2C; Table IV), slightly higher than in PMF and control cells (Fig. 2D and E; Table IV).

A differ situation was observed in localization of both ERK1 and ERK2 antigens recognized by ERK1/2 antibody (Fig. 2F-I; Table IV). In contrast to ERK2, the expression patterns of ERK1/2 antibody in PV and other analysed subtypes of MPN were independent of the presence of JAK2V617F mutation. The analysed epitopes were not observed in most cell nuclei of PV (Fig. 2F; Table IV), whereas in the nucleus of ET, PMF and control group they occurred richly (Fig. 2G-I; Table IV). The cytoplasm of all examined tissues were characterized by high expression of epitopes that react with ERK1/2 antibody (Fig. 2F-I; Table IV). They could be detected in high levels in the cytoplasm of ET and in normal cells (Fig. 2G and I; Table IV); smaller amounts was present in PV cells (Fig. 2F, Table IV) and only trace amounts could be localized in PMF cells (Fig. 2H; Table IV). Single cells of normal trephine biopsies were extremely rich in these epitopes; expression in these single cells was higher than expression in the nucleus of these cells (Fig. 2I). The control IHC reaction performed by omitted primary antibodies resulted in a complete lack of the brown signal (not shown).

Dot blot assay results. Data obtained from our IHC studies was further confronted by dot blot analysis. As illustrated in Fig. 3 and Table V, we observed that protein extracts derived from JAK2V617F positive cases of PV, ET and PMF were characterized by the abundant occurrence of pSTAT5 


\section{pSTAT5 protein expression}

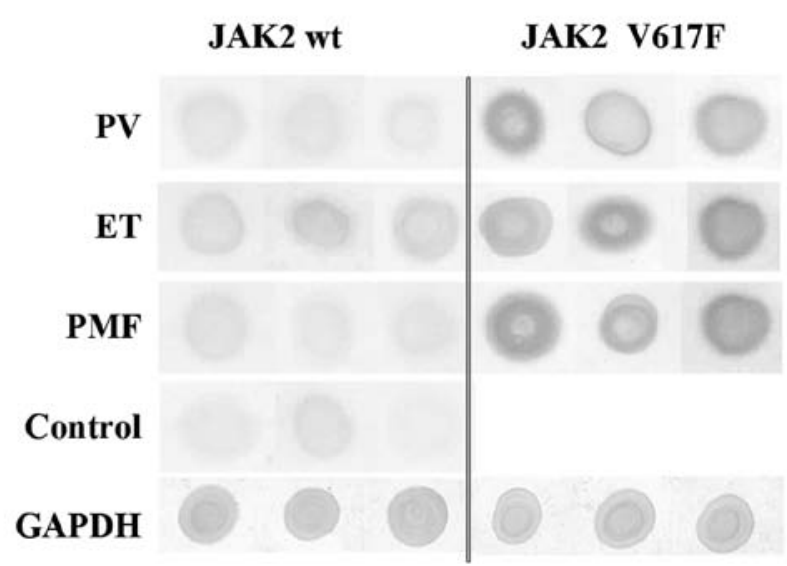

Figure 3. Immunodetection of pSTAT5 in protein extract by dot-blotting in MPN patients, both without and with JAK2V617F mutation and also in healthy control.

Table V. The presence and relative abundance of phosphorylated STAT5 protein and unphosphorylated ERK2 and ERK1/2 proteins in the protein extracts isolated from patients with $\mathrm{PV}$, ET, PMF and healthy controls.

\begin{tabular}{lcccc}
\hline & \multicolumn{2}{c}{ phospho-STAT5 } & & \\
\cline { 2 - 3 } Patients & JAK2 wt & JAK2 V617F & ERK2 & Total-ERK1/2 \\
\hline PV & + & ++ & ++ & ++ \\
ET & + & ++ & ++ & ++ \\
PMF & + & ++ & ++ & ++ \\
Control & tr. & nd. & ++ & ++ \\
\hline
\end{tabular}

nd., not determined; tr., antigen present in trace amounts; +, antigen present; ++, antigen present in abundance.

antigens (Fig. 3). However, proteins from JAK2 wild-type cases showed relatively lower pSTAT5 antigen content. Control cases are only scarcely represented by protein of interest (Fig. 3, Table V). These results coincide with the results of IHC reactions (Fig. 1), which are described in the Results section.

Additionally, we did not see differences between expression levels of ERK antigens bound by ERK2 or ERK1/2 antibodies. These epitopes appear in abundance in all analysed proteins, extracted from bone marrow tissues (Table V).

Comparison of the expression levels of STAT5 a gene between all analysed MPN subtypes. We determined whether statistically significant differences of STAT5a and ERK2 protein expression, which were observed between various disease among MPNs, after IHC and dot-blot reactions are reflected in the RNA level.

Whichever of eleven calibrators was chosen in order to determinate relative STAT5a gene expression level, the results were always similar and statistically significant $(\mathrm{p}<0.001)$.
When we did not take into consideration JAK2V617F mutation status, we could observe approximately 5-fold higher expression level of STAT5a gene in PV in comparison to the patients with PMF and approximately 2-fold higher than in ET. Similarly, patients with ET displayed approximately 2-fold higher STAT5a mRNA levels compared to patients with PMF (Fig. 4A). Further comparison, revealed that in any case the highest STAT5a gene expression level was positively correlated with the presence of JAK2V617F mutation; patients who were tested positive for JAK2V617F were characterized by high expression of STAT5a gene. RT-qPCR results coincide with the results of the IHC and dot-blot staining for the presence of phosphorylated form of STAT5 protein.

Relative levels of ERK2 transcripts are similar in each of the three MPN subtypes. We also examined the expression levels of ERK2 gene as shown in Fig. 4B. ERK2 expression in patients with ET and PV was approximately 1.5 times higher as compared to patients with PMF. Whichever of the eleven calibrators was selected, the results were similar and not statistically significant ( $\mathrm{p}=0.566-1.000$; Table IV). These results only partially overlap with IHC and dot-blot studies. Statistical analysis confirmed the observations performed under a light microscope.

\section{Discussion}

The results of our study demonstrate different levels as well as various expression patterns of antigens recognized by phospho-STAT5, ERK2 and total ERK1/2 antibodies within bone marrow trephine biopsies from patients with PV, ET, PMF and in healthy subjects. Differential expressions of these proteins were observed both in the megakaryocytes and in other haemopoietic cells. It seems that these differences of proteins/genes expressions, visible under the light microscope, onto membrane after performing dot-blot reaction and after RT-qPCR could allow to classify each sample to one of 3 types of MPNs in a simpler manner, sometimes without checking JAK2V617F mutation status.

We believe that our findings are particularly important, especially because, as it is well known, the most common MPN JAK2V617F mutation alone cannot explain the phenotypic heterogeneity of PV, ET and PMF. It should also be noted that even in healthy persons, the V617F version of JAK2 kinase may be recognize, but with a low frequency (10\%). Phenotypic manifestation of MPNs depends on V617F dosage, therefore in these people clinical signs of MPNs were never developed (32). In the MPN patients who lack V617F mutation, other but less common genetic alternations have been described: including mutations in exon 12 of JAK2 (33) and in exon 10 of thrombopoietin receptor gene (MPL) (34). The first one may be found only in PV with a low frequency, estimated at approximately $3 \%(33,35)$. The second alternation, resulting in several common variants of mutation in codon 515 of MPL gene, W515A/K/L, are described only in patients with ET and PMF but also in only small percentage, approximately $1 \%$ and $10 \%$, respectively $(34,36-38)$.

Furthermore, in ET and PMF patients other than the abovementioned mutations in MPL gene have been described: MPL 
A

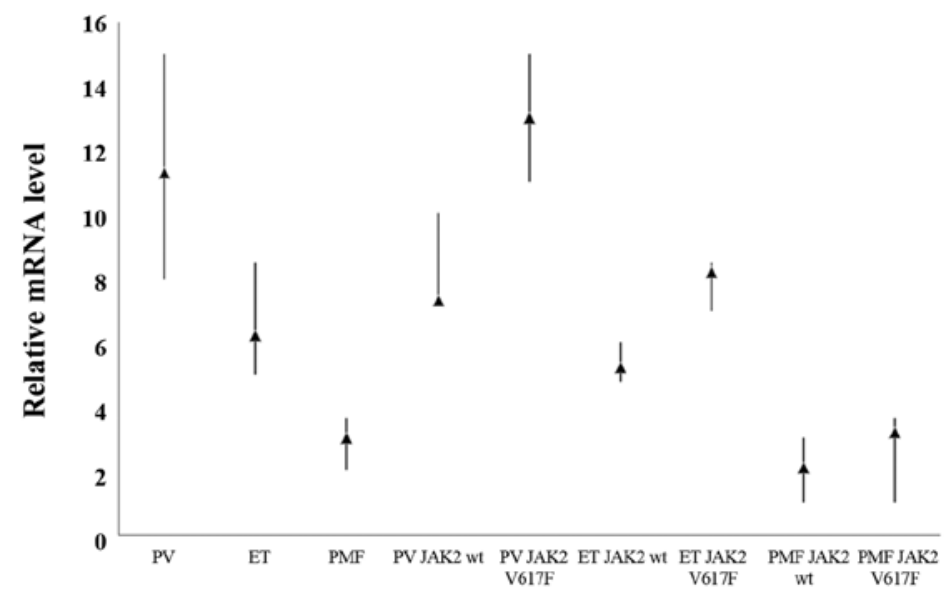

B

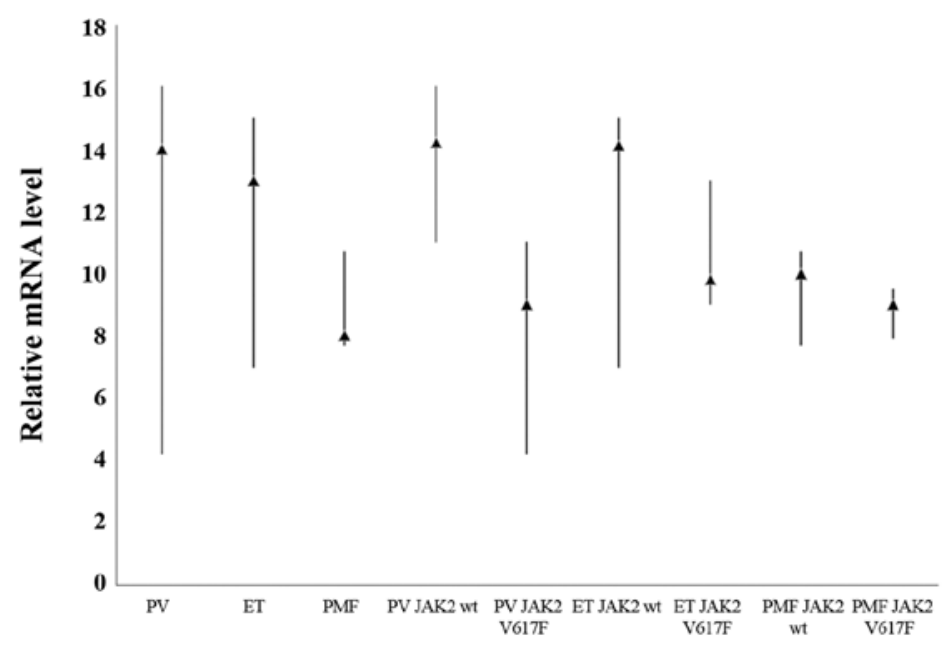

Figure 4. Relative levels of pSTAT5a (A) and ERK2 (B) mRNA transcripts in PV, ET and PMF, determined by real-time semi-quantitative PCR. The graph shows maximum, minimum and median ( $\mathbf{\Lambda}$ ) values of the data set.

S505N, W515Ki, W515Kii, W515R and W515A. They were present both in patients who are V617F-negative and V617Fpositive, and also in low frequency, up to $12 \%$ (39). To date, in MPNs, aberrations were additionally described in several subsequent genes, e.g. in TET2, ASXL1, DNMT3A, LNK IDH1, IDH2, CBL, CALR, SH2B3 and EZH2 gene (40,41), with different, but always relatively low frequency in PV, ET and $\mathrm{PMF}$ entities, in $\mathrm{JAK}^{-}$and/or $\mathrm{JAK}^{+}, \mathrm{MPL}^{-}$and/or $\mathrm{MPL}^{+}$ patients. The evidence described above encourages to pursue other morphological and molecular features to be used for better characterization of the three phenotypes of MPN. This, in turn, can help to provide: a much better understanding of MPNs pathophysiology, and the establishment of appropriate diagnostic algorithm to monitor diseases.

We selected STAT5 molecule to our study because out of seven members of STAT family (STAT1, STAT2, STAT3, STAT4, STAT5a, STAT5b, STAT6) only three, STAT3, STAT5a and STAT5b were predominantly phosphorylated by JAK2V617F kinase in hematopoietic disorders (42). As a result of phosphorylation, closely related STAT5a and STAT5b proteins are activated. They form heterodimers (43) and then they are translocated from the cytoplasm into the nucleus where they act as transcription factors regulating multiple target gene expression with anti-apoptotic function. These target genes are responsible for cell cycle progression, cell growth and survival (43). JAK2V617F phosphorylate STAT5a only at tyrosine 694 and STAT5b only at tyrosine 699. In addition, STAT5 proteins could also directly lead to the activation of RAF/MEK/ERK signalling cascades, where ERK1 and ERK2 are downstream proteins $(44,45)$. These proteins were phosphorylated at threonine 202 (ERK1) and tyrosine 204 (ERK2) and they are ready to activate the next downstream elements of signaling pathway. Reduced STAT5, STAT3 and ERK1/2 expression in human HEL cells with JAK2V617F mutation, was observed as a result of JAK2 inhibition by WP1066 inhibitor treatment (46). This result shows that STAT5 and ERK proteins are associated with JAK2 kinase pathway. In addition, Pircher and colleagues $(44,45)$ indicated that ERK proteins cooperate with STAT5a and they are necessary for full activation of STAT5a protein.

Upon examining the bone marrow trephines derived from patients with PV, ET and PMF we found some interesting data 
concerning STAT5 protein and gene expressions. The first one and, at the same time, the easiest to observe is not surprising, because it had also been shown by others investigators. STAT5 protein expression phosphorylated on 694 tyrosine residues was enhanced only in MPNs with JAKV617F mutation. Similar results have been reported by James et al (11) and Shide et al (23), who observed an increasing level of phosphoSTAT5 proteins in transgenic mice expressing JAKV617F. Sometimes high level of STAT5 expression is used as surrogate marker of JAKV617F mutation (47).

In our study we reported the differences in pSTAT5 protein expression level and intracellular expression pattern in megakaryocytes and other hematopoietic cells. Previously, these differences have not been described in detail. The differences in expression level of STAT5 between the wild-type-JAK2 and JAK2V617F were clear in almost every cases, but they were statistically significant only for ET and PMF. We reported that in ET and PMF patients, with JAK2V617F mutation, pSTAT5 antigens are concentrated primarily in the nucleus of bone marrow cells, whereas the cytoplasm is completely devoid of signal or only scarcely labelled (Fig. 1F-G). However, in PV with JAK2V617F and in PV, ET, PMF with wild-type JAK2, pSTAT5 is observed both in the nucleus and in the cytoplasm of hematopoietic cells (Fig. 1B), and the expression pattern of these antigens is different in each disease among MPNs. We have also observed different patterns of pSTAT5 protein expression in megakaryocytes.

In most MPN cases (except PV with JAK2-negative), pSTAT5 were present predominantly in the nucleus of megakaryocytes, and their cytoplasm was usually free of signal (Fig. 1B and C, E-G, inside images). However, in PV with wild-type of JAK2 kinase pSTAT5 gave positive signal in both cell organelles, but in the cytoplasm expression was more abundant (Fig. 1A, inside). As reported by others $(48,49)$, in the cytoplasm, STAT5a protein cooperated with Gab2 protein and it was associated with cell proliferation through activation of PIK3/AKT signalling cascade. High nuclear expression of pSTAT5 in megakaryocytes of PV, ET and PMF has already been reported and interpreted by others researchers as abnormal (50) because pSTAT5 protein expression in megakaryocytes of healthy cases is restricted only to the cytoplasm. The results of our experiment in this respect are in agreement with previous reported by Gibson et al (50). On the contrary, Grimwade and co-authors (51) have suggested that intracellular localization of STAT5 protein, phosphorylated on 694 tyrosine residue, in megakaryocytes depends on the type of pSTAT5 antibody used.

This work also demonstrated extremely high transcription level of STAT5a gene by using RT-qPCR in patients with JAK2V617 mutation compared to the individuals without this mutation. Expression level of STAT5a gene in PV patients revealed approximately 5 times higher RNA level compared to the patients with PMF and approximately 2-fold higher than in ET. These results were of course statistically significant, and simultaneously they suggest that STAT5a RT-qPCR assay could be a good diagnostic tool even without checking JAK2V617F status.

We suggest that when we bind these results from IHC studies concerning phosphor-STAT5 protein expression with RT-qPCR analysis, clear distinction of the three subtypes of
MPNs is possible and relatively simple. However, our studies should be broaden by increasing the number of subjects in order to answer the question whether different patterns of pSTAT5 expression are in fact characteristic for each entities or not. To the best of our knowledge, this kind of intracellular difference between the three phenotypes of MPNs observed and described here by us has not been described in detail before.

We also compared the expression of antigens recognized by ERK2 and ERK1/2 antibodies in MPNs and in healthy controls and we found a variety of differences. To the best of our knowledge, this is the first report which demonstrated different intracellular localization of ERK proteins in MPNs. At first, we showed that ERK expression is independent of the presence of JAK2V617F mutation, with one exception, in PV where clearly visible differences in distribution of ERK2 antigens were visible (Fig. 2A and B). The highest expression levels of ERK2 antigens were observed only in approximately $30 \%$ of the nucleus with JAK2V617F mutation and in approximately $80 \%$ with wild-type JAK2 kinase (Fig. 2A and B). The cytoplasm in JAK2V617F cells is free of signal. This kind of ERK2 expression pattern in PV patients allows to distinguish tissue samples derived from patients with and without JAK2V617F mutation. However, localization of both ERK1 and ERK 2 antigens by using total ERK1/2 antibodies revealed opposite results. Firstly, the expression was independent of the presence of JAKV617F mutation and secondly it was localized only in the cytoplasm. Nuclei were free of signal. Such significant differences in intracellular localization of ERK2 and ERK1/2 antigens may result from the fact that, as suggested by the manufacturer of ERK1/2 antibodies, these molecules could recognize ERK1 more readily than ERK2 antigens. It seems that in our experiment this situation appears to be most likely. It is worth noting at this moment that, as reported by others, ERK2 has pro-proliferative effects on the cells, while ERK1 is anti-proliferative (52).

We concluded that differences in expression pattern of ERK2 antigens may be helpful in distinguishing PV and ET from PMF. ERK2 expression in PV and ET were relatively stronger than in PMF and, additionally, concentrated rather in the nucleus (Fig. 2A-C). Cytoplasm was less marked. In PMF, the intensity of signal both in nucleus and cytoplasm was on a similar level (Fig. 2A-D). It should be observed that dot-blot analysis and RT-qPCR did not revealed differences between expression levels of ERK2 gene among the MPN entities. In our opinion, using antibodies binding to both ERK1 and ERK2 proteins also allows to distinguish PV and ET from PMF. In most of PV cells, the signal is concentrated in the cytoplasm, whereas in ET and PMF it was localized both in the cytoplasm and nucleus. Additionally, we observed that in ET the expression level is relatively stronger than in PMF but these differences were not statistically significant. The mechanisms leading to the accumulation of STAT5 and ERK2 proteins in the cell nucleus remain poorly elucidated. We speculate that it could be associated with the presence JAKV617F and/or MPL W515 alterations because these molecules (i.e. JAK2 and MPL) are known as regulators of JAK/STAT and RAF/MAP/ ERK signalling pathways.

However, in future research, we should increase the number of subjects and the number of antibodies directed to different epitopes of STAT5 and ERK1/2 proteins and then 
again describe in details the expression levels and patterns of these antigens, similarly to this report. Here we used only small number of cases of each disease and only one antibody to pSTAT5 protein and two antibodies directed to ERK protein.

\section{Acknowledgements}

This study was supported by the Polish National Science Center (NCN), project no. N N401 153538 and by the Grant of Nicolaus Copernicus University, project no. 05/2010. The authors would like to thank Anna Michalska-Orlik for her professional linguistic editing of the manuscript.

\section{References}

1. Kavalerchik E, Goff D and Jamieson CH: Chronic myeloid leukemia stem cells. J Clin Oncol 26: 2911-2915, 2008.

2. Li S, Kralovics R, De Libero G, Theocharides A, Gisslinger H and Skoda RC: Clonal heterogeneity in polycythemia vera patients with JAK2 exon12 and JAK2-V617F mutations. Blood 111: 38633866, 2008.

3. Laibe S, Tadrist Z, Arnoulet C, Sainty D and Mozziconacci MJ: A myeloproliferative disorder may hide another one. Leuk Res 33: 1133-1136, 2009.

4. Tam CS, Nussenzveig RM, Popat U, Bueso-Ramos CE Thomas DA, Cortes JA, Champlin RE, Ciurea SE, Manshouri T, Pierce SM, et al: The natural history and treatment outcome of blast phase BCR-ABL- myeloproliferative neoplasms. Blood 112: $1628-1637,2008$

5. Abdel-Wahab O, Mullally A, Hedvat C, Garcia-Manero G, Patel J, Wadleigh M, Malinge S, Yao J, Kilpivaara O, Bhat R, et al: Genetic characterization of TET1, TET2, and TET3 alterations in myeloid malignancies. Blood 114: 144-147, 2009.

6. Campbell PJ and Green AR: The myeloproliferative disorders. N Engl J Med 355: 2452-2466, 2006

7. Baxter EJ, Scott LM, Campbell PJ, East C, Fourouclas N, Swanton S, Vassiliou GS, Bench AJ, Boyd EM and Curtin N; Cancer Genome Project: Acquired mutation of the tyrosine kinase JAK2 in human myeloproliferative disorders. Lancet 365 : 1054-1061, 2005

8. Kralovics R, Passamonti F, Buser AS, Teo SS, Tiedt R, Passweg JR, Tichelli A, Cazzola M and Skoda RC: A gain-offunction mutation of JAK2 in myeloproliferative disorders. N Engl J Med 352: 1779-1790, 2005

9. Levine RL, Wadleigh M, Cools J, Ebert BL, Wernig G Huntly BJ, Boggon TJ, Wlodarska I, Clark JJ, Moore S, et al: Activating mutation in the tyrosine kinase JAK 2 in polycythemia vera, essential thrombocythemia, and myeloid metaplasia with myelofibrosis. Cancer Cell 7: 387-397, 2005.

10. Zhao R, Xing S, Li Z, Fu X, Li Q, Krantz SB and Zhao ZJ: Identification of an acquired JAK2 mutation in polycythemia vera. J Biol Chem 280: 22788-22792, 2005.

11. James C, Ugo V, Le Couédic JP, Staerk J, Delhommeau F, Lacout C, Garçon L, Raslova H, Berger R, Bennaceur-Griscelli A, et al: A unique clonal JAK2 mutation leading to constitutive signalling causes polycythaemia vera. Nature 434: 1144-1148, 2005.

12. Pradhan A, Lambert QT, Griner LN and Reuther GW: Activation of JAK2-V617F by components of heterodimeric cytokine receptors. J Biol Chem 285: 16651-16663, 2010.

13. Dahabreh IJ, Giannouli S, Zoi C, Zoi K, Voulgarelis M and Moutsopoulos HM: Management of hypereosinophilic syndrome: A prospective study in the era of molecular genetics. Medicine (Baltimore) 86: 344-354, 2007.

14. Dahabreh IJ, Giannouli S, Zoi C, Zoi K, Loukopoulos D and Voulgarelis M: Hypereosinophilic syndrome: Another face of janus? Leuk Res 32: 1483-1485, 2008.

15. Jones AV, Kreil S, Zoi K, Waghorn K, Curtis C, Zhang L, Score J, Seear R, Chase AJ, Grand FH, et al: Widespread occurrence of the JAK2 V617F mutation in chronic myeloproliferative disorders. Blood 106: 2162-2168, 2005.

16. Steensma DP, Dewald GW, Lasho TL, Powell HL, McClure RF, Levine RL, Gilliland DG and Tefferi A: The JAK2 V617F activating tyrosine kinase mutation is an infrequent event in both 'atypical' myeloproliferative disorders and myelodysplastic syndromes. Blood 106: 1207-1209, 2005.
17. Tefferi A and Vardiman JW: Classification and diagnosis of myeloproliferative neoplasms: The 2008 World Health Organization criteria and point-of-care diagnostic algorithms. Leukemia 22: 14-22, 2008.

18. Baker SJ, Rane SG and Reddy EP: Hematopoietic cytokine receptor signaling. Oncogene 26: 6724-6737, 2007.

19. Morgan KJ and Gilliland DG: A role for JAK2 mutations in myeloproliferative diseases. Annu Rev Med 59: 213-222, 2008.

20. Wernig G, Mercher T, Okabe R, Levine RL, Lee BH and Gilliland DG: Expression of Jak2V617F causes a polycythemia vera-like disease with associated myelofibrosis in a murine bone marrow transplant model. Blood 107: 4274-4281, 2006.

21. Lacout C, Pisani DF, Tulliez M, Gachelin FM, Vainchenker W and Villeval JL: JAK2V617F expression in murine hematopoietic cells leads to MPD mimicking human PV with secondary myelofibrosis. Blood 108: 1652-1660, 2006.

22. Tiedt R, Hao-Shen H, Sobas MA, Looser R, Dirnhofer S, Schwaller J and Skoda RC: Ratio of mutant JAK2-V617F to wild-type Jak2 determines the MPD phenotypes in transgenic mice. Blood 111: 3931-3940, 2008.

23. Shide K, Shimoda HK, Kumano T, Karube K, Kameda T, Takenaka K, Oku S, Abe H, Katayose KS, Kubuki Y, et al: Development of ET, primary myelofibrosis and PV in mice expressing JAK2 V617F. Leukemia 22: 87-95, 2008

24. Steensma DP, McClure RF, Karp JE, Tefferi A, Lasho TL, Powell HL, DeWald GW and Kaufmann SH: JAK2 V617F is a rare finding in de novo acute myeloid leukemia, but STAT3 activation is common and remains unexplained. Leukemia 20: 971-978, 2006.

25. Vizmanos JL, Ormazábal C, Larráyoz MJ, Cross NC and Calasanz MJ: JAK2 V617F mutation in classic chronic myeloproliferative diseases: A report on a series of 349 patients. Leukemia 20: 534-535, 2006.

26. Akada H, Yan D, Zou H, Fiering S, Hutchison RE and Mohi MG: Conditional expression of heterozygous or homozygous Jak2V617F from its endogenous promoter induces a polycythemia vera-like disease. Blood 115: 3589-3597, 2010.

27. Choi S-E, Hong SW and Yoon SO: Proposal of an appropriate decalcification method of bone marrow biopsy specimens in the era of expanding genetic molecular study. J Pathol Transl Med 49: 236-242, 2015.

28. Dziaman T, Ludwiczak H, Ciesla JM, Banaszkiewicz Z, Winczura A, Chmielarczyk M, Wisniewska E, Marszalek A, Tudek B and Olinski R: PARP-1 expression is increased in colon adenoma and carcinoma and correlates with OGG1.PLoS One, 9: e115558, 2014.

29. Burduk PK, Bodnar M, Sawicki P, Szylberg Ł, Wiśniewska E, Kaźmierczak W, Martyńska M and Marszałek A: Expression of metalloproteinases 2 and 9 and tissue inhibitors 1 and 2 as predictors of lymph node metastases in oropharyngeal squamous cell carcinoma. Head Neck 37: 418-422, 2015.

30. Remmele W and Stegner HE: Recommendation for uniform definition of an immunoreactive score (IRS) for immunohistochemical estrogen receptor detection (ER-ICA) in breast cancer tissue. Pathologe 8: 138-140, 1987 (In German).

31. Pfaffl MW: A new mathematical model for relative quantification in real-time RT-PCR. Nucleic Acids Res 29: e45, 2001.

32. Sidon P,El Housni H, Dessars B and Heimann P: The JAK2V617F mutation is detectable at very low level in peripheral blood of healthy donors. Leukemia 20: 1622, 2006.

33. Scott LM, Tong W, Levine RL, Scott MA, Beer PA, Stratton MR, Futreal PA, Erber WN, McMullin MF, Harrison CN, et al: JAK2 exon 12 mutations in polycythemia vera and idiopathic erythrocytosis. N Engl J Med 356: 459-468, 2007.

34. Pikman Y, Lee BH, Mercher T, McDowell E, Ebert BL, Gozo M, Cuker A, Wernig G, Moore S, Galinsky I, et al: MPLW515L is a novel somatic activating mutation in myelofibrosis with myeloid metaplasia. PLoS Med 3: e270, 2006.

35. Pardanani A, Lasho TL, Finke C, Hanson CA and Tefferi A: Prevalence and clinicopathologic correlates of JAK2 exon 12 mutations in JAK2V617F-negative polycythemia vera. Leukemia 21: 1960-1963, 2007.

36. Pardanani AD, Levine RL, Lasho T, Pikman Y, Mesa RA, Wadleigh M, Steensma DP, Elliott MA, Wolanskyj AP, Hogan WJ, et al: MPL515 mutations in myeloproliferative and other myeloid disorders: A study of 1182 patients. Blood 108: 3472-3476, 2006

37. Chaligné R, Tonetti C, Besancenot R, Roy L, Marty C, Mossuz P, Kiladjian JJ, Socié G, Bordessoule D, Le Bousse-Kerdilès MC, et al: New mutations of MPL in primitive myelofibrosis: Only the MPL W515 mutations promote a G1/S-phase transition. Leukemia 22: 1557-1566, 2008. 
38. Beer PA, Campbell PJ, Scott LM, Bench AJ, Erber WN, Bareford D, Wilkins BS, Reilly JT, Hasselbalch HC, Bowman R, et al: MPL mutations in myeloproliferative disorders: Analysis of the PT-1 cohort. Blood 112: 141-149, 2008.

39. Boyd EM, Bench AJ, Goday-Fernández A, Anand S, Vaghela KJ Beer P, Scott MA, Bareford D, Green AR, Huntly B, et al: Clinical utility of routine MPL exon 10 analysis in the diagnosis of essential thrombocythaemia and primary myelofibrosis. Br J Haematol 149: 250-257, 2010.

40. Michiels JJ, Valster F, Wielenga J, Schelfout K and De Raeve H: European vs 2015-World Health Organization clinical molecular and pathological classification of myeloproliferative neoplasms World J Hematol 4: 16-53, 2015. doi: 10.5315/wjh.v4.i3.16.

41. Pasquier F, Cabagnols X, Secardin L, Plo I and Vainchenker W: Myeloproliferative neoplasms: JAK2 signaling pathway as a central target for therapy. Clin Lymphoma Myeloma Leuk 14 (Suppl): S23-S35, 2014.

42. Ihle JN and Gilliland DG: Jak2: Normal function and role in hematopoietic disorders. Curr Opin Genet Dev 17: 8-14, 2007.

43. Ihle JN: STATs: Signal transducers and activators of transcription. Cell 84: 331-334, 1996.

44. Pircher TJ, Flores-Morales A, Mui AL, Saltiel AR, Norstedt G, Gustafsson JA and Haldosén LA: Mitogen-activated protein kinase kinase inhibition decreases growth hormone stimulated transcription mediated by STAT5. Mol Cell Endocrinol 133: 169-176, 1997.

45. Pircher TJ, Petersen H, Gustafsson JA and Haldosén LA: Extracellular signal-regulated kinase (ERK) interacts with signal transducer and activator of transcription (STAT) 5a. Mol Endocrinol 13: 555-565, 1999.

46. Verstovsek S, Manshouri T, Quintás-Cardama A, Harris D, Cortes J, Giles FJ, Kantarjian H, Priebe W and Estrov Z: WP1066, a novel JAK2 inhibitor, suppresses proliferation and induces apoptosis in erythroid human cells carrying the JAK2 V617F mutation. Clin Cancer Res 14: 788-796, 2008.
47. Aboudola S, Murugesan G, Szpurka H, Ramsingh G, Zhao X, Prescott N, Tubbs RR, Maciejewski JP and Hsi ED: Bone marrow phospho-STAT5 expression in non-CML chronic myeloproliferative disorders correlates with JAK2 V617F mutation and provides evidence of in vivo JAK2 activation. Am J Surg Pathol 31: 233-239, 2007.

48. Nyga R, Pecquet C, Harir N, Gu H, Dhennin-Duthille I, Régnier A, Gouilleux-Gruart V, Lassoued K and Gouilleux F: Activated STAT5 proteins induce activation of the PI 3-kinase/ Akt and Ras/MAPK pathways via the Gab2 scaffolding adapter. Biochem J 390: 359-366, 2005.

49. Rosa Santos SC, Dumon S, Mayeux P, Gisselbrecht S and Gouilleux F: Cooperation between STAT5 and phosphatidylinositol 3-kinase in the IL-3-dependent survival of a bone marrow derived cell line. Oncogene 19: 1164-1172, 2000.

50. Gibson SE, Schade AE, Szpurka H, Bak B, Maciejewski JP and Hsi ED: Phospho-STAT5 expression pattern with the MPL W515L mutation is similar to that seen in chronic myeloproliferative disorders with JAK2 V617F. Hum Pathol 39: 1111-1114, 2008.

51. Grimwade LF, Happerfield L, Tristram C, McIntosh G, Rees M, Bench AJ, Boyd EM, Hall M, Quinn A, Piggott N, et al: Phospho-STAT5 and phospho-Akt expression in chronic myeloproliferative neoplasms. Br J Haematol 147: 495-506, 2009.

52. Levy DE and Darnell JE Jr: Stats: Transcriptional control and biological impact. Nat Rev Mol Cell Biol 3: 651-662, 2002. 